\title{
Políticas de transferência de renda no Brasil e na Argentina
}

ROSA MARIA MARQUES*

Income-transfer policies in Brazil and Argentina. This article deals with the conditioned income-transfer developed by the governments of Lula and Dilma, in the Brazilian case, and by Cristina Fernández de Kirchner, in Argentina. In other words, the programs Bolsa Família and "Asignación Universal por Hijo para Protección Social". They are comparatively analyzed with regard to their institutionality, the access criteria, the conditionings and the concept of poverty, in order to discuss whether they constitute or not a social right and the relative importance of the amount given.

Keywords: conditioned income-transfer policies; Bolsa Família; Asignación Universal por Hijo para Protección Social.

JEL Classification: I30; I38.

\section{INTRODUÇÃO}

Atualmente, vários países da América Latina se destacam por desenvolverem políticas de transferência de renda condicionada, o que tem chamado a atenção dos cientistas sociais das mais diferentes áreas. Entre as diversas experiências, destacam-se: o Programa Bolsa Família, no Brasil; o Programa de Desarrollo Humano Oportunidades, no México; o Sistema Chile Solidário, no Chile; o Programa Juntos,

\footnotetext{
"Professora titular do Departamento de Economia e do Programa Pós-graduados em Economia Política da Pontifícia Universidade Católica de São Paulo (PUCSP), E-mail: rosamkmarques@gmail.com. Este artigo se insere no esforço de pesquisa de um estudo comparado entre Brasil e Argentina com relação ao sistema público de aposentadoria e às transferências de renda condicionadas, realizado com o apoio da Coordenação de Aperfeiçoamento de Pessoal de Nível Superior (CAPES), mediante a concessão de uma bolsa Estágio Sênior. Aqui são tratadas as políticas de transferência de renda. A autora agradece os comentários e sugestões de Maria Lúcia T. Garcia (UFES) e Berenice Rojas Couto (PUCRS). Submetido: 20/Agosto/2011; aprovado: 6/Agosto/2012.
} 
no Peru; e, mais recentemente, a Asignación Universal por Hijo para Proteción Social, na Argentina.

Esses e outros programas integram uma segunda geração de políticas assistenciais introduzida na região (SOLANO, 2009), adotadas depois que ficou patente que as políticas macroeconômicas neoliberais empreendidas pelos governos latino-americanos tiveram como resultado a persistência da pobreza e o aumento significativo do número de pessoas em situação de "vulnerabilidade social", ${ }^{1}$ na expressão utilizada pela Comissão Econômica para a América Latina e o Caribe (CEPAL, 2000). Naquele momento, essa instituição não só apontava que 220 milhões de pessoas viviam em estado de pobreza, o que correspondia a $45 \%$ da população total da região, como também enfatizava que aumentou a quantidade de domicílios com condições de vida instável, cuja renda familiar estava constantemente cruzando a linha de pobreza, o que produzia o aumento da chamada "rotação da pobreza". Naquele momento, a CEPAL denunciou que a vulnerabilidade social constituía traço característico do padrão de desenvolvimento vigente nesses países, durante os anos 1990. A partir dessa caracterização, a CEPAL levantava a necessidade do resgate das políticas públicas universais, especialmente na área da saúde e da educação, da elevação do nível das aposentadorias e pensões de valores mais baixos e da promoção de maior solidariedade. Essa solidariedade seria traduzida, imediatamente, em aumento da progressividade tributária, exigindo maior contribuição das rendas e patrimônios mais elevados, seja de pessoas ou de empresas. A partir da elevação da tributação dos mais ricos, portanto, seria promovida a universalização de políticas públicas essenciais.

Essa recomendação ia de encontro ao receituário da maioria dos organismos internacionais e daqueles que continuavam a defender a supremacia do mercado. O Banco Mundial, por exemplo, defendia a tese de que não houve redução da pobreza porque havia problemas de "governança". Para ele, seria necessário promover o melhor desempenho do setor público, mediante redução de gastos e aumento da eficiência, e garantir que os recursos fossem utilizados no combate à pobreza, o que seria obtido, de forma eficiente, pela ação das organizações não governamentais, dos sindicatos e das organizações profissionais (BANCO MUNDIAL, 2000).

A persistência da miséria e da pobreza na América Latina foram resultados de duas décadas (1980 e 1990) de programas de estabilização e de ajuste estrutural adotados na região. Esses programas, em nome da supremacia do mercado, foram acompanhados por medidas de desregulamentação e de flexibilização do mercado

\footnotetext{
${ }^{1}$ A expressão "vulnerabilidade social” remete à consideração das características dos indivíduos como responsáveis por sua situação. Com isso, deixa-se de levar em conta que, na sociedade capitalista, os diferentes segmentos sociais e econômicos estão submetidos à lógica da acumulação do capital. Se no plano da aparência os setores pobres ou muito pobres parecem estar excluídos, integram o chamado exército industrial de reserva, viabilizando taxas de exploração elevadas (MARX, 1982).
} 
de trabalho, o que se traduziu em precarização e aumento da informalidade, em um quadro de elevada taxa de desemprego. Do lado das políticas sociais, principalmente no campo das aposentadorias e dos cuidados da saúde, foi promovido o avanço da privatização (Fleury, 1998; Andrenacci; Repetto, 2006), ao mesmo tempo em que foi realizado algum tipo de política focalizada, muitas vezes associada a programas de participação comunitária, na qual o enfoque é trabalhar com os “ativos" disponíveis da população alvo.

É possível se observar que em meados dos anos 1990, para alguns países, e principalmente nos anos 2000, para diversos países da região, fatores políticos, sociais e econômicos induziram à criação de uma nova geração de políticas sociais associadas ao combate à pobreza. Segundo a Cepal (2009, p.94), essa reformulação expressou "o reconhecimento dos escassos avanços em matéria de redução da pobreza" ocorridos durante os anos 1990. As políticas focalizadas de segunda geração apresentam-se, antes de tudo, como políticas "massivas" (dado o número de pessoas por elas contempladas), contrastando com aquelas voltadas a determinadas comunidades, típicas das políticas focalizadas de primeira geração. Segundo Solano (2009), ao se referir a um trabalho do Programa de las Naciones Unidas para el Desarrollo (PNUD) e a outro do Banco Mundial, todos os programas que integram essa nova geração de políticas sociais focalizadas têm pelo menos três elementos em comum: o foco em famílias pobres ou extremamente pobres, com crianças e adolescentes; o princípio da contrapartida (ou condicionalidade) e a idéia de "acumulação de capital humano"2 no longo prazo.

Este artigo tem por objetivo analisar comparativamente dois dos programas/ políticas da segunda geração, isto é, o Programa Bolsa Família (BF) e a Asignación Universal por Hijo (AUH), desenvolvidos no Brasil e na Argentina, respectivamente. Os aspectos analisados são: a) a forma como essas políticas se relacionam com o sistema público de proteção social, isto é, sua institucionalidade, de modo a configurar um direito ou uma "benesse"; b) a ideia ou não de transitoriedade da situação de pobreza; c) a importância relativa dos benefícios concedidos e os critérios de acesso que definem os beneficiários ou "clientelas". Com exceção da importância relativa dos benefícios, que é analisada em relação ao salário mínimo e ao Produto Interno Bruto (PIB), os demais aspectos seguem os utilizados para a caracterização de um benefício social, tanto no país como internacionalmente. Eles são, portanto, parte integrante de sua legislação.

Além dessa introdução e das considerações finais, o artigo está dividido em duas partes: a primeira é dedicada a descrever o Programa Bolsa Família e da Asignación Universal por Hijo, fundamental para o entendimento de seu desenho

\footnotetext{
${ }^{2}$ Isto é, que os beneficiários das políticas, principalmente as crianças e os adolescentes, iriam portar capacidades qualitativamente diferentes que seus genitores, decorrentes do exercício das contrapartidas exigidas.
} 
e concepção. A segunda parte trata da análise de seus aspectos propriamente ditos.

\section{DESCRIÇÃO DOS PROGRAMAS / POLÍTICAS E ALGUNS DE SEUS IMPACTOS}

\section{Programa Bolsa Família}

O Programa Bolsa Família é o principal instrumento de transferência de renda existente no Brasil, caso não se considere aqueles que integram a Seguridade Social, tal como o Benefício de Prestação Continuada (BPC) e o piso do Regime Geral de Previdência Social (RGPS) pago aos trabalhadores rurais e urbanos. ${ }^{3} \mathrm{O}$ BF é de responsabilidade do Ministério de Desenvolvimento Social e Combate à Fome (MDS), ministério criado no início do primeiro governo Lula(2002-2006). Em artigo anterior, analisou-se o impacto do Programa Bolsa Família na decisão das eleições presidenciais e concluiu-se que esse programa auxiliou na formação de uma nova base social de apoio ao governo Lula, diferente da sua tradicional, isto é, ligada aos sindicatos, aos movimentos sociais e ao Partido dos Trabalhadores (Marques et al, 2009). Essa é a mesma conclusão a que chega André Singer (2009).

O BF foi instituído em outubro de 2003 mediante a Medida Provisória 132, convertida na Lei 10.836, de 9 de janeiro de 2004. A partir de sua vigência, os programas então existentes - Programa Nacional de Renda Mínima vinculado à Educação - Bolsa Escola (2001), o Programa Nacional de Acesso à Alimentação — PNAA (2003), o Programa Nacional de Renda Mínima vinculada à Saúde Bolsa Alimentação (2001) e o Programa Auxílio-Gás (2002) — foram extintos.

Em junho de 2011, o BF atendia 12.436.167 famílias em todo território nacional, isto é, em todos os 5.565 municípios do país. ${ }^{4}$ Considerando que as famílias pobres têm em média 4,4 membros, ${ }^{5}$ esse programa beneficiou, em junho de 2010, $28,56 \%$ da população brasileira. O BF concede benefícios a famílias em situação de extrema pobreza (definida como renda mensal per capita inferior a $\mathrm{R} \$ 70,00$ )

\footnotetext{
${ }^{3}$ A Seguridade Social compreende o RGPS (garante aposentadorias e pensões aos trabalhadores formais que estão vinculados ao setor privado da economia; o piso equivale a um salário mínimo), o Sistema Único de Saúde (sistema público; garante a atenção integral à saúde), a Assistência Social (concede um benefício - BPC -, de caráter não contributivo, de valor igual ao salário mínimo, à pessoa com deficiência, de qualquer idade, incapacitada para a vida independente e para o trabalho, e aos idosos com 65 anos ou mais, cuja renda familiar per capita bruta seja inferior a 25\% do salário mínimo vigente) e o Seguro Desemprego (benefício pago ao trabalhador formal desocupado). Em 2010, o BPC beneficiou mensalmente 1,6 milhão de pessoas com deficiência e 1,5 milhão de idosos (dados disponíveis no site do MDS - www.mds.gov.br).

${ }^{4}$ Dado disponível no site do MDS.

${ }^{5}$ Segundo a Secretaria Nacional de Renda e Cidadania do MDS.
} 
e a famílias em situação de pobreza (definida como renda mensal per capita entre $\mathrm{R} \$ 70,01$ e R \$ 140,00). Consiste de um benefício de valor básico, de R \$ 70,00, sem condicionalidade, pago às famílias em situação de extrema pobreza, e de dois benefícios variáveis. O primeiro benefício variável, de $\mathrm{R} \$ 32,00$, é pago pela ocorrência de filho entre zero e quinze anos de idade, até o máximo de três filhos. $\mathrm{O}$ segundo benefício variável, de $\mathrm{R} \$ 38,00$, é pago por ocorrência de filho com 16 a 17 anos de idade, até o máximo de dois filhos. Dessa forma, o valor do BF varia de $\mathrm{R} \$ 70,00$ a R $\$ 242,00 .{ }^{6}$ O benefício é pago mensalmente, mediante cartão da Caixa Econômica Federal. ${ }^{7}$ Os benefícios variáveis estão condicionados à frequência escolar mínima (de 87\%, para as crianças e adolescentes entre 6 e 15 anos de idade; de 75\%, para os estudantes entre 16 e 17 anos); e, na área da saúde, ao acompanhamento da vacinação e do crescimento e desenvolvimento das crianças menores de 7 anos; ao acompanhamento das mulheres de 14 a 44 anos, à realização de pré-natal no caso de gestantes, e, no caso de nutrizes, ao acompanhamento de sua saúde e de seu bebê.

A estimativa da quantidade de famílias pobres e muito pobres (indigentes) é realizada pelo Instituto Brasileiro de Geografia e Estatística (IBGE), mas as informações relativas às famílias, em cada município, integram o Cadastro Único para Programas Sociais, monitorado pelo MDS. Isso não invalida a utilização de outras estatísticas de outros institutos, com o objetivo de monitorar a qualidade da informação (Boyadjian, 2009). Destaque-se que as informações relativas aos beneficiários do BF são de domínio público, de forma que qualquer pessoa pode acessar o banco de dados administrado pela Caixa Econômica Federal e ver, para cada município brasileiro, o nome e a data de nascimento da pessoa responsável pelo recebimento do benefício, bem como de seus filhos. ${ }^{8}$ Ressalte-se, ainda, que o artigo $23^{\circ}$ da Lei 10.836/2004 garante que a mulher será preferencialmente a titular do cartão de benefícios, dando ênfase ao papel da mãe na estrutura familiar, muito embora o BF utilize o conceito de unidade nuclear e não de unidade familiar. ${ }^{9}$

Em 2010, o gasto com o Programa Bolsa Família foi de R \$ 13.493,3 milhões,

\footnotetext{
${ }^{6}$ No caso das famílias migradas dos programas que foram extintos quando da criação do BF sofrerem diminuição do valor do benefício, a lei 10.836 , em seu artigo $2^{\circ}$, garante o pagamento de um Benefício Variável de Caráter Extraordinário, cujo valor é calculado caso a caso (Brasil, 2004).

${ }^{7}$ Ao contrário da AUH, o valor integral do benefício é entregue ao beneficiário mensalmente.

${ }^{8}$ Há um debate entre os pesquisadores da área e afins sobre a legitimidade desse nível de transparência, pois os beneficiários do BF são os únicos a que o grande público tem acesso sem restrições, muito embora os valores pagos não estejam individualizados. No meu entender, isso caracteriza um estigma da pobreza, em nada contribuindo para a melhoria da gestão do programa.

${ }^{9}$ A escolha da mulher como titular está de acordo com várias experiências internacionais. Segundo o parágrafo $1^{\circ}$ do artigo $2^{\circ}$, é considerada a "unidade nuclear, eventualmente ampliada por outros indivíduos que com ela possuam laços de parentesco ou de afinidade, que forme um grupo doméstico, vivendo sob o mesmo teto e que se mantém pela contribuição de seus membros” (Brasil, 2004, p.1).
} 
o equivalente a $0,37 \%$ do PIB. De 2005 (quando o BF estava implantado em todos os municípios) a 2010, a despesa em termos reais praticamente dobrou, mas a proporção do PIB elevou-se somente em 0,05\% (ANFIP, 2011). Neste ano, seu financiamento foi praticamente custeado com recursos da Contribuição para Financiamento da Seguridade Social (COFINS), tributo da esfera federal.

A gestão do BF é descentralizada e compartilhada pela União, pelos estados, pelo Distrito Federal e pelos municípios. Dessa forma, os entes federados são parceiros na implantação e no controle do Programa Bolsa Família e na alimentação do Cadastro Único para Programas Sociais (CUPS). O governo federal paga diretamente aos beneficiários através da Caixa Econômica Federal e repassa para os municípios os recursos necessários para a gestão do programa. $\mathrm{O}$ valor desse repasse depende do Índice de Gestão Descentralizada do Município (IGD-M), mecanismo criado pelo governo federal para monitorar e incentivar o desempenho da gestão. ${ }^{10}$

A distribuição regional do BF, como não poderia deixar de ser, é fortemente concentrada na região Nordeste $(51,34 \%)$, a mais pobre do país, seguida da região Sudeste $(24,73 \%)$, a mais populosa. A distribuição das famílias beneficiárias, por estado e regiões, pode ser vista na Tabela 1.

Desde o início da implantação do BF vários estudos foram realizados para estudar diversos aspectos de seu impacto. Em 2005, por exemplo, foi demonstrado que, para vários municípios, a soma dos benefícios pagos representava montante superior à receita disponível (receita provinda de arrecadação própria, mais as transferências constitucionais) em mais do que 40\% (Marques, 2005). Em 2007, foi evidenciado que os beneficiários do BF não apresentavam maior nível de cobertura vacinal do que a população de baixa renda não coberta pelo programa (Sawyer, 2007).

A esses, seguiram-se vários estudos que estimaram o impacto do BF na redução da pobreza e da extrema pobreza, na desigualdade de renda, na permanência da criança na escola, entre outros. Estimativa baseada nas informações da Pesquisa Nacional por Amostra de Domicílios (PNAD), realizada pelo IBGE, calculou que, em 2003, um ano antes do início da implantação do Programa Bolsa Família, $12 \%$ da população brasileira estava abaixo da linha de pobreza (defini-

\footnotetext{
${ }^{10}$ O IGD-M é calculado com base em quatro fatores: 1) operação, formada pela média aritmética da qualidade e integridade das informações constantes no CUPS, pela atualização da base de dados, pelas informações da frequência escolar, pelas informações sobre o acompanhamento das condicionalidades da área da saúde; 2) adesão, que expressa se o município aderiu ao Sistema Único de Assistência Social; 3) informação da apresentação da comprovação de gastos dos recursos do IGD-M, que indica se o gestor registrou no SUASWEB a mencionada comprovação de gastos ao Conselho Municipal de Assistência Social; e 4) informação da aprovação total da comprovação dos gastos dos recursos do IGD-M pelo Conselho Municipal de Assistência Social. O peso atribuído a cada fator no cálculo do índice, os valores mínimos exigidos para cada fator, bem como os incentivos, entre outros determinantes do valor a ser repassado para o município podem ser encontrados no site do MDS em http://www.mds.gov.br/ bolsafamilia/gestaodescentralizada/gestao-descentralizada-municipal-igd-m.
} 
da internacionalmente como US\$ PPC 1,25 dia $)^{11}$ e que, em 2008, essa taxa havia caído para $4,8 \%$. A pobreza, por sua vez, caiu de $26,1 \%$ para $14,1 \%$ da população (IPEA, 2010).

No tocante à desigualdade da renda, Soares et al (2010) mostram que $16 \%$ da redução observada entre 1999 e 2009 se deve ao Bolsa Família, muito embora a renda desse benefício não chegue a $0,8 \%$ da renda das famílias. A aparente contradição dessas participações é explicada pela focalização do programa, isto é, pelo fato de ser destinado aos mais pobres. Em relação à pobreza e à extrema pobreza, considerando as rendas per capita máximas para concessão do benefício básico e variável, esses pesquisadores, ao analisarem a evolução da queda observada desde 1990, apontam o aceleramento da queda com a presença do BF (Soares et al, 2010).

Já em relação à frequência escolar, a pesquisa de Silveira Neto (2010) aponta que o BF é responsável pelo aumento de 2,2 pontos percentuais na frequência. Esse impacto é de 2,2 pontos percentuais no meio urbano e de 3,0 pontos percentuais no meio rural. Em termos regionais, foi maior no Nordeste (2,2 pontos percentuais) do que na região Sudeste (1,5 pontos percentuais). Para se dimensionar a importância desses resultados, é preciso se levar em conta que a frequência escolar na região Sudoeste já era de 97,3\% e, no Nordeste, de 95,7\%.

Quanto aos resultados da aplicação da condicionalidade da área da saúde, embora não haja pesquisas direcionadas para este fim, alguns indicadores permitem se inferir que houve melhora da situação de saúde da população beneficiária. Esse foi o caso da participação das crianças de zero a quatro anos com peso abaixo do esperado no total das crianças da mesma faixa de idade (passou de 4,8\%, em 1996, para $1,8 \%$, em 2006). Além disso, a queda na taxa de mortalidade infantil de menores de um ano de idade, que continuou sua trajetória descendente, foi bem mais expressiva no nordeste do que em outras regiões, sugerindo que a melhora da alimentação e o acompanhamento da gestante, da nutriz e do bebê podem ter influído no desempenho desse indicador (IPEA, 2010). ${ }^{12}$

Por último, quanto à existência de possíveis fraudes no BF, Soares e Leichsenring, com base nas informações levantadas pelo Tribunal de Contas da União, estimam que apenas 1,09\% dos benefícios são fraudulentos. Esse dado, além de esclarecer que a realidade do programa é diferente daquela que algumas vezes é vinculada nos principais jornais e meios televisivos do país, indica que o custo de um estrito controle seria provavelmente mais elevado do que a redução de gasto que poderia provocar.

\footnotetext{
${ }^{11}$ Essa unidade está referida à Paridade do Poder de Compra (PPC) de U\$1,25 nos Estados Unidos.

${ }^{12}$ Para o Brasil, a taxa de mortalidade infantil caiu de 22,6 (2004) para 19 (2008). No mesmo período, na região nordeste, a taxa foi de 32,7 e 26,7. Apesar da redução das taxas, nacional e regionais, seus níveis ainda são elevados.
} 
Tabela 1: Distribuição regional das famílias beneficiárias do Programa Bolsa Família, junho de 2011

\begin{tabular}{|c|c|c|}
\hline Região / Estados & $\mathrm{N}^{\circ}$ de famílias & $\%$ \\
\hline Região Norte & 1.304 .402 & 10,49 \\
\hline Acre & 53.717 & \\
\hline Amazonas & 275.579 & \\
\hline Amapa & 46.378 & \\
\hline Pará & 657.824 & \\
\hline Rondônia & 103.946 & \\
\hline Roraima & 43.761 & \\
\hline Tocantins & 123.197 & \\
\hline Região Nordeste & 6.385 .327 & 51,34 \\
\hline Alagoas & 399.629 & \\
\hline Bahia & 1.582 .916 & \\
\hline Ceará & 1.012 .607 & \\
\hline Maranhão & 873.599 & \\
\hline Paraíba & 456.340 & \\
\hline Pernambuco & 1.066 .665 & \\
\hline Piauí & 428.008 & \\
\hline Rio Grande do Norte & 334.011 & \\
\hline Sergipe & 231.552 & \\
\hline Região Centro Oeste & 679.894 & 5,47 \\
\hline Distrito federal & 77.821 & \\
\hline Goiás & 316.058 & \\
\hline Mato Grosso do Sul & 128.420 & \\
\hline Mato Grosso & 157.595 & \\
\hline Região Sudeste & 3.075 .491 & 24,73 \\
\hline Espirito Santo & 182.136 & \\
\hline Minas Gerais & 1.081 .872 & \\
\hline Rio de Janeiro & 655.019 & \\
\hline São Paulo & 1.156 .464 & \\
\hline Região Sul & 991.053 & 7,97 \\
\hline Paraná & 431.413 & \\
\hline Rio Grande do Sul & 429.376 & \\
\hline Santa Cataria & 130.264 & \\
\hline Total & 12.436 .167 & \\
\hline
\end{tabular}

Elaboração própria a partir dos dados da Caixa Econômica Federal 


\section{Asignación Universal por Hijo para Protección Social}

A Asignación Universal por Hijo para Protección Social (AUHPS) foi implementada na Argentina em 1/11/2009, mediante o Decreto 1602/09. Essa medida deu prosseguimento ao processo de retomada pelo Estado da responsabilização da proteção social, cujo marco maior foi a (re)estatização das aposentadorias, pensões e demais benefícios, em dezembro de 2008 (Argentina, 2008; Golbeert, 2010).

O AUHPS consiste de um benefício pago às crianças e adolescentes menores de 18 anos, residentes no país, ou incapacitados sem limite de idade, que sejam argentinos nativos ou naturalizados ou com residência legal no país mínima de 3 anos, que pertençam a famílias cujos pais se encontram desempregados, exerçam atividade doméstica ou exerçam atividade na economia informal. No caso dos desempregados, não podem estar recebendo o seguro desemprego e, no caso dos dois últimos, a remuneração não pode ser superior a um salário mínimo.

Com esse decreto, a presidente Cristina Fernandez de Kirchner, promoveu a ampliação da cobertura da alocação por filho, dado que o mesmo já existia para os trabalhadores do mercado formal de trabalho. Dessa maneira, passaram a coexistir dois subsistemas de AUH, um contributivo (dos trabalhadores formais) e outro não contributivo (DL 1602/09).

O subsistema contributivo, regido pela Lei 24.714 de outubro de 1996, concede, entre outros benefícios, um pagamento mensal por cada filho menor de 18 anos de idade a cargo do trabalhador registrado, isto é, do mercado formal de trabalho. Esse benefício é financiado por contribuições patronais de uso exclusivo (7,5\% sobre o total das remunerações dos trabalhadores — artigo $5^{\circ}$ da Lei 24.714) e seu valor depende da faixa em que se enquadre a remuneração do trabalhador. ${ }^{13}$ De maneira geral, o valor do benefício vigente em maio de 2010 seguia o que é apresentado na Tabela 2.

Tabela 2: AUH, subsistema contributivo, maio de 2010, pesos

\begin{tabular}{l|l}
\hline \multicolumn{1}{c}{ Faixa de remuneração } & \multicolumn{1}{c}{ Valor do benefício por filho } \\
\hline Entre 100 e 2400 pesos & $\$ 180$ \\
Entre 2400,01 e 3600 pesos & $\$ 136$ \\
Entre 3600,01 e 4800 pesos & $\$ 91$ \\
\hline Faixa de remuneração & Valor do benefício por filho \\
\hline Entre 100 e 2400 pesos & $\$ 180$ \\
\hline Entre 2400,01 e 3600 pesos & $\$ 136$ \\
\hline Entre 3600,01 e 4800 pesos & $\$ 91$
\end{tabular}

Fonte: Administración Nacional de la Seguridad Social — ANSES, 2010

\footnotetext{
${ }^{13}$ Para algumas zonas econômicas, o valor máximo da remuneração da última faixa é maior.
} 
Os trabalhadores com remuneração acima de $\$ 4800$ pesos não têm direito à AUH. Contudo, ao declarem sua remuneração para efeito do imposto de renda, podem deduzir a parcela correspondente ao gasto por filho, de valor definido pelas autoridades fiscais, tal como acontece no Brasil. Segundo cálculos da Administración Nacional de la Seguridade Social (ANSES, 2010), a alocação implícita aumenta conforme a remuneração, mas não supera os $\$ 180$ pagos para a primeira faixa de remuneração da $\mathrm{AUH} .{ }^{14}$

O subsistema não contributivo, Asignación Universal por Hijo para Protección Social (AUHPS), consiste de um benefício mensal de \$180, por filho, ${ }^{15}$ até um máximo de 5 filhos. ${ }^{16}$ Desse montante, $80 \%$ são pagos diretamente e $20 \%$ são depositados em uma conta, podendo ser retirados uma vez ao ano, quando o responsável pela criança e/ou adolescente precisa comprovar a frequencia escolar e o cumprimento do calendário de vacinação e demais controles de saúde definidos pelo Ministério da Saúde. Seu financiamento é feito com recursos da ANSES, ${ }^{17}$ também sendo previsto a utilização da rentabilidade do Fundo de Garantia de Sustentabilidade do Sistema Integrado Provisional Argentino (artigo $3^{\circ}$ do DL $1.602 / 09)$.

Em março de 2010, a AUHPS atingia 3.518.248 crianças, sendo 49,07\% do gênero feminino e $50,93 \%$ do gênero masculino. Em termos de idade, $57,8 \%$ tinham de zero a nove anos, $28,1 \%$ de dez a quatorze anos e $14,01 \%$ maior de quatorze (ANSES, 2010). A distribuição geográfica e a taxa de cobertura podem ser vistas na Tabela 3.

Segundo simulação realizada pela ANSES, o gasto previsto para 2010 (de 0,6\% do PIB estimado para esse ano), teria um impacto na demanda agregada entre $1,5 \%$ e 1,8\% do PIB (ANSES, 2010). Já em termos de redução da pobreza e da indigência, a estimativa de D'Elia, com base em dados da Encuesta Permanente de Hogares do terceiro trimestre de 2009, realizada pelo Instituto Nacional de Estadística y Censos, era de uma redução de $30 \%$ e $55 \%$, respectivamente, de forma que a pobreza se reduziria de $13,9 \%$ para $9,7 \%$ e a indigência de $4 \%$ para $1,9 \%$ (D'elia et al. O). ${ }^{18}$ impacto da AUHPS sobre a pobreza e a indigência, na Grande Buenos Aires foi de $32,6 \%$ e $68,4 \%$, respectivamente (Agis et al, s. n.). Estimativa realizada por Roca

\footnotetext{
${ }^{14}$ No Brasil, também os pagantes de imposto de renda se beneficiam de uma dedução por filho ou dependente. Em 2011, isso correspondia a R \$ 1.808,28. Além disso, são dedutíveis as despesas de instrução até o limite de 2.830,84 e parte das despesas com saúde.

${ }^{15} \mathrm{O}$ valor por filho era de $\$ 280$ em julho de 2011 e o valor para filho deficiente era de $\$ 720$ em maio de 2010 e de $\$ 880$ em julho de 2011.

${ }^{16}$ Também está previsto o benefício por filho deficiente.

${ }^{17}$ Os recursos da ANSES consistem de contribuições: da arrecadação do Imposto sobre os Bens Pessoais não incorporados ao Processo Econômico, de recursos adicionais que anualmente o Congresso fixe na Lei de Orçamento; do resultado de juros, multas e moras; e da renda proveniente de aplicações financeiras.

${ }^{18}$ Para o INDEC, as famílias pobres são aquelas cujo rendimento familiar não supera a Canastra Básica Total, e as indigentes aquelas cujo rendimento familiar não supera a Canastra Básica Alimentar. Para a definição das Canastras, ver Encuesta Permanente de Hogares em http://www.indec.mecon.ar/ principal.asp?id_tema $=9556$.
} 
considera que a implantação do AUHPS reduziu em 42,3\% o número de famílias indigentes e em $21,9 \%$ o número das famílias pobres (ROCA, 2011).

Tabela 3: Distribuição geográfica das crianças e adolescentes beneficiários da AUHPS e taxa de cobertura por região, maio/2010

\begin{tabular}{l|c|c|c}
\hline \multicolumn{1}{c|}{ Regiões } & $\begin{array}{c}\text { No de crianças } \\
\text { e adolescentes }\end{array}$ & $\begin{array}{c}\text { Participação } \\
\text { noTotal }\end{array}$ & $\begin{array}{c}\text { Taxa de } \\
\text { cobertura (a) }\end{array}$ \\
\hline Grande B.Aires & 110382 & 3,14 & 18,54 \\
Noroeste & 626956 & 17,82 & 33,88 \\
Nordeste & 499665 & 14,20 & 34,86 \\
Patagônica & 133701 & 3,80 & 20,63 \\
Cuyo & 256941 & 7,30 & 27,16 \\
Pampeana & 1890603 & 53,74 & 28,05 \\
Total & 3518248 & 100,00 & - \\
\hline
\end{tabular}

Fonte: ANSES, 2010

Segundo Tirenni (s. d.), com a introdução da AUHPS, desapareceram programas e planos em todo o país, entre os quais, no plano federal, o Plano Famílias para Inclusão Social e o Plano Chefes e Chefas de Lar Desempregados.

\section{ANÁLISE COMPARADA ENTRE O BOLSA FAMÍLIA E A ASIGNACIÓN UNIVERSAL POR HIJO PARA PROTECCIÓN SOCIAL}

\section{Benesse ou direito?}

Ao se comparar a institucionalidade dos benefícios concedidos pelo BF e a AUHPS, verifica-se que estão situados em campos bem distintos da proteção social. $\mathrm{O} \mathrm{BF}$, amparado por lei própria, é um programa e não um direito, e não integra a Seguridade Social. ${ }^{19}$ Afora ser chamado de Programa, colabora para essa compreensão não só o fato de os artigos $1^{\circ}$ da Medida Provisória 132 e da Lei 10.836 situarem o BF no "âmbito da Presidência da República", como o fato de explicitarem que o "poder executivo deverá compatibilizar a quantidade de beneficiários do Programa Bolsa Família com as dotações orçamentárias existentes" (parágrafo único do artigo $6^{\circ}$, p. 2). Isso significa que a concessão do benefício está condicionada à existência de recurso, o que não acontece com os benefícios garantidos pelo Regime Geral da Previdência Social (RGPS) e com o Benefício de Prestação Continuada (BPC). Tanto no RGPS como no BPC, o direito ao benefício é dado pelo cumprimento dos critérios de acesso e não pela disponibilidade de recursos.

\footnotetext{
${ }^{19}$ No Brasil, o direito é concedido aos segurados de baixa renda, tal como descrito anteriormente. Nesse caso, os valores pagos são inferiores ao do Bolsa Família. Os trabalhadores do mercado informal não têm nenhum tipo de cobertura, caso não estejam no nível de renda de corte do BF.
} 
Ademais, o BF não integra a Seguridade Social, constituindo-se num programa de governo. Isso significa que, no plano jurídico, ele pode sofrer descontinuidade ou até mesmo ser extinto no caso de um novo presidente ter entendimento diverso com relação às estratégias de combate à pobreza. Isso não quer dizer que a promoção de sua extinção seja politicamente fácil de ser realizada, tal é seu impacto em termos de população beneficiária e, em vários casos, a importância relativa dos recursos recebidos pelas famílias no âmbito do município (Marques, 2005).

Mas, embora o BF não integre a Seguridade Social — os artigos 203 e 204 da Constituição brasileira, que tratam da Assistência Social, não incorporaram nenhuma referência a esse programa -, a Lei 10.836 faz menção a seus recursos. Diz em seu artigo $6^{\circ}$ :

“As despesas do Programa Bolsa Família correrão à conta das dotações alocadas nos programas federais de transferência de renda e no Cadastramento Único a que se refere o parágrafo único do art. $1^{\circ}$, bem como de outras dotações do Orçamento da Seguridade Social da União que vierem a ser consignadas ao Programa” (Lei 10.836, p. 2).

E como mencionado anteriormente, recursos da Cofins têm sido alocados para financiar o BF. A utilização dessa fonte constitui mais uma entre tantas alterações sofridas pelo que foi desenhado para ser a Seguridade Social, em 1988. Embora em termos de volume, os recursos alocados no BF sejam relativamente pequenos, em comparação com os gastos dos diferentes ramos da Seguridade Social, isso aprofunda a disputa existente entre eles e facilita o discurso do déficit do RGPS (Ugino e Marques, 2011).

Já a AUHPS não é um programa e sim um direito social, pois é fruto da universalização da Asignación Universal por Hijo, que passou a conceder recursos monetários também para as crianças e adolescentes de famílias de baixa renda que atuam no mercado informal ou estão desempregados. A AUHPS é, portanto, um subsistema não contributivo da AUH e integra a proteção social pública argentina. Além disso, o acesso ao benefício independe de dotação orçamentária própria, sendo financiado pelos recursos da ANSES.

Mas embora a criação da AUHPS se configure uma universalização de um direito social pré-existente, o acesso e o número de filhos são diferenciados. No caso da AUHPS, o decreto 1602/09 define o benefício, concedido a no máximo 5 filhos, como condicionado à frequência escolar e ao cumprimento dos controles de saúde definidos pelo Ministério da Saúde, o que não está presente na Lei 24714/96, voltada para os trabalhadores formais. Essa diferença de explicitação dá margem a se entender a AUHPS como um direito menor ou rebaixado, quando comparado à alocação dos trabalhadores formais.

A diferenciação de tratamento é ainda sentida no pagamento efetuado em duas partes: uma mensal e outra anual, condicionada à comprovação da frequência escolar e do cumprimento das exigências no campo da saúde. Comparado ao Programa Bolsa Família, o uso do pagamento anual como forma de controle das condicionalidades parece ser mais oneroso, pois envolve o custo da manutenção das contas individuais. 


\section{A transitoriedade do fato gerador do benefício}

Tanto o BF como a AUHPS têm como fundamento a transitoriedade da situação do beneficiário. No caso do Programa Bolsa Família, o suposto é que a concessão do benefício e a exigência das condicionalidades criam as condições para a superação da pobreza, isto é, para uma renda superior aos umbrais da pobreza. No caso do benefício monetário, sua simples transferência eleva o nível de renda da família; no caso das condicionalidades, especialmente a frequência escolar, a hipótese é que as crianças e adolescentes estarão mais preparados para poderem ingressar no mercado de trabalho e auferirem rendimentos mais elevados do que seus pais. Essa hipótese é fortemente influenciada pela teoria do capital humano, onde os atributos do indivíduo definem sua inserção no mercado de trabalho. Nesse sentido, a superação da pobreza é dada pelos filhos e não pelos pais. Tendo em vista o pouco tempo de existência desse programa, nenhuma pesquisa pôde ainda confirmar ou rejeitar essa hipótese.

A transitoriedade presente na Asignación Universal por Hijo para Protección Social é a informalidade ou o desemprego. Não é a renda, como no Bolsa Família. No preâmbulo do decreto 1602/09, três fatos são reconhecidos para justificar a criação da AUHPS: a) que as alocações então vigentes não incluíam os grupos familiares desocupados ou que trabalhavam na economia informal; b) que a Lei 26.061 , de novembro de 2005, trata a proteção integral às crianças e adolescentes; c) que apesar de as políticas desenvolvidas pelo governo argentino terem produzido uma melhora da situação econômica do país, o que resultou no aumento da ocupação e na redução do níveis de pobreza e de marginalidade, persistiam situações de exclusão de diversos setores da população. Vale destacar que, no preâmbulo, ainda está explicitado que sozinho o benefício monetário não resolverá a situação financeira dos segmentos mais pobres da população, tal como segue:

"Que, forzoso es decirlo, esta medida por si no puede garantizar la salida de la pobreza de sus beneficiarios y no puede ubicarse alli toda la expectativa social, aunque resultará, confiamos, um paliativo importante. Queremos evitar entonces el riesgo de depositar la ilusión de que com una sola media se puede terminar com la pobreza. Que, como se ha destacado, una medida de tal naturaleza tiene sin embargo una indudable relevancia en cuanto significa más dinero em los bolsillos de los sectores más postergados. No implica necesariamente el fin de la pobreza, pero inocultablemente ofrece una respuesta reparadora a una población que ha sido castigada por políticas económicas de corte neoliberal"(Decreto 1602/09, pp. 3 - 4).

Assim, na medida em que o crescimento econômico promover o aumento do emprego informal, o objeto da AUHPS deve diminuir.

De certa maneira, a extensão da alocação familiar por filho para as famílias na informalidade ou desocupadas (mesmo com suas condicionalidades) constitui uma resposta à deterioração expressiva que o mercado de trabalho argentino sofreu devido às políticas neoliberais implantadas nos anos 1990 e devido à crise econômica 
dos anos 1998 - 2002, quando o PIB diminui significativamente. Em 2002, o desemprego atingiu a taxa de $21,5 \%$ da população economicamente ativa e a participação dos trabalhadores assalariados sem registro no total dos trabalhadores assalariados chegou a $38,4 \%$. Em 2009, quando foi criada a AUHPS, a taxa de desemprego estava em $8,8 \%$ e os trabalhadores assalariados em registro constituíam $36,2 \%$ do total dos trabalhadores assalariados (AGIS et al, s. n.). ${ }^{20}$

\section{A importância relativa do benefício e o critério de acesso}

Esta parte do artigo tem como objetivo destacar o quanto representa a transferência de renda praticada pelo governo argentino e brasileiro em relação ao salário mínimo e ao PIB de cada país. Vale lembrar que, em 2010, a Organização Internacional do Trabalho estimou que o salário mínimo argentino (expresso por sua capacidade de poder de compra) era $60 \%$ maior do que o brasileiro (OIT, 2010).

$\mathrm{Na}$ comparação entre o valor dos benefícios pagos pelo Programa Bolsa Família e a Asignación Universal por Hijo para Protección Social, o primeiro representava, em junho de $2011,5.87 \%$, 6.97\% e $12.84 \%$ do salário mínimo para, respectivamente, filho até 15 anos de idade, de 16 a 17 anos ou para o benefício básico, para o qual não há condicionalidade. Já a AUHPS, na faixa de renda menor considerada, o benefício pago por filho representava, em maio de $2010,12 \%$ do salário mínimo da época. Na hipótese da família brasileira ser extremamente pobre (e por isso receber o benefício básico), ter três filhos com idade de até 15 anos e dois entre 16 e 17 anos, a renda a ela transferida corresponde a $4 ., 40 \%$ do valor do salário mínimo. Caso a família não seja considerada extremamente pobre, esse percentual cai para $31.56 \%$. Na Argentina, por cinco filhos, o valor pago representa $60 \%$ do salário mínimo.

$\mathrm{Na}$ comparação entre os dois mecanismos de transferência, é preciso ainda se considerar o valor pago ao filho deficiente, muito embora, no Brasil, isso esteja na esfera da Assistência Social e não no BF, mediante a concessão de um salário mínimo para as famílias com renda per capita de até $25 \%$ do salário mínimo. No caso da Argentina, embora o valor do benefício seja menor, correspondendo a $48 \%$ do salário mínimo, o limite superior da renda considerada representa 3,2 salários mínimos. Se consideramos uma família de sete membros, com cinco filhos, o per capita atinge 45,71\% do salário mínimo, bem maior do que o limite exigido no Brasil.

Do ponto de vista da importância relativa do gasto enquanto esforço da nação, o esforço para a implementação do Bolsa Família é menor do que para a Asignación Universal por Hijo para Protección Social $(0.37 \%$ do PIB e $0.6 \%$ do PIB, respectivamente). Comparado aos gastos com os diferentes ramos da proteção social do Brasil e da Argentina, tanto uma como a outra são políticas relativamente baratas. Para se ter uma idéia, em 2010, o gasto com os benefícios previdenciários dos trabalhadores do setor privado da economia, largamente determinados

\footnotetext{
${ }^{20}$ Para o leitor brasileiro, o nível de informalidade dos assalariados argentinos pode parecer pequeno, dado que, no Brasil, só recentemente houve um forte aceleramento da formalização, superior ao crescimento da população ocupada (IBGE, 2011).
} 
pelas aposentadorias, representou 6,93\% do PIB, no Brasil. No mesmo ano, as três esferas de governo gastaram com o sistema público de saúde brasileiro o equivalente a $3.7 \%$ do PIB (ANFIP, 2011). Segundo a Cepal, ${ }^{21}$ o conjunto das ações e serviços de proteção social desenvolvidos na Argentina, em 2005, correspondia a 19,4\% do PIB (CEPAL, s.n)

Embora essas políticas não envolvam grande quantidade de recursos, têm grande efeito multiplicador. Em termos econômicos, no Brasil, muitas vezes os recursos destinados às famílias constituem um aporte muito significativo para o município, tal como já foi comentado. Além disso, estudos apontam que a quase totalidade dos recursos são destinados ao consumo, fomentando a economia local (Landim Junior, 2009; Duarte et al, 2009).

Em relação ao critério de acesso, tanto BF como AUHPS adotam a aplicação de linhas de pobreza e de indigência e destinam-se mesma quantidade de filhos(cinco), com a ressalva que no caso brasileiro isso somente aconteceu a partir de dezembro de 2007, mais de dois anos depois do inicio da implantação do programa.

É digno de nota, ainda, o fato de o BF ter um componente sem condicionalidade, cujo benefício é dirigido para a população considerada extremamente pobre. Esse componente apresenta-se como um embrião de uma renda mínima garantida, embora contemple somente as famílias de mais baixa renda. De qualquer forma, esse componente tem como fundamento o reconhecimento do direito das famílias disporem de um mínimo de renda e o entendimento que o Estado deve garantir o acesso a este mínimo. Mesmo se o seu valor é considerado baixo, sua simples existência pode vir a ser um instrumento para que, no futuro, se possa garantir a todo cidadão uma renda adequada as suas necessidades, independentemente de seu papel no processo produtivo e social.

\section{CONSIDERAÇÕES FINAIS}

Embora o Programa Bolsa Família e a Asignación Universal por Hijo para Protección Social possam ser enquadrados como expressões das políticas de segunda geração que estão sendo implantadas na América Latina nos últimos anos, dado que exigem condicionalidades, apresentam diferenças expressivas entre si.

A primeira delas diz respeito ao fato de que o BF não é um direito e não se integra à proteção social contemplada pela Seguridade Social, enquanto que a AUHPS é um direito e constitui um subsistema não contributivo da alocação familiar concedido pela ANSES. Esse direito, entretanto, ao estar vinculado a condicionalidades, configura-se em um direito menor ou rebaixado, como se fosse necessário diferenciar ou penalizar aqueles que recebem o benefício porque não houve prévia contribuição. No caso brasileiro, o fato de o governo utilizar recursos da Seguridade Social para financiar o Bolsa Família não auxilia na compreensão de sua natureza e pode ser mais um elemento na disputa por recursos entre os ramos da Seguridade.

${ }^{21}$ A Cepal não explicita, mas provavelmente o gasto se refere às três esferas de governo. 
A segunda diferença significativa está nos valores pagos, bem mais expressivos no caso Argentino, quando calculados em termos do salário mínimo dos países. Como foi demonstrado anteriormente, o valor do benefício pago pela AUHPS é praticamente o dobro do praticado no Brasil. Em termos do volume do gasto, também o governo argentino despende mais do que o brasileiro, proporcionalmente ao PIB.

A terceira diferença digna de nota é o componente sem condicionalidade presente no BF. A existência de um benefício básico, dirigido às famílias extremamente pobres, sem que lhes seja exigido o cumprimento de qualquer condicionalidade, pode ser entendida como um embrião de renda mínima garantida, apesar de apenas dirigida para a população miserável.

Por último, pelo menos ao nível do discurso, os dois programas parecem estar embasados em concepções diferentes: pobreza e pobreza decorrente da informalidade e da desocupação. Enquanto o Programa Bolsa Família aposta na superação da pobreza mediante as mudanças que a educação promoveria na renda dos filhos dos beneficiários, a AUHPS vê o benefício como emergencial e considera que o fato gerador do benefício será superado pela interação de múltiplos fatores, mas dando ênfase ao crescimento econômico no que se refere à diminuição da informalidade e do desemprego.

\section{REFERÊNCIAS BIBLIOGRÁFICAS}

AGIS, Emmanuel, CAÑETE, Carlos; PANIGO, Demian. (2011) "El impacto de la Asignación Universal por hijo en Argentina”. Disponível: http://www.ceil-piette.gov.ar/docpub/documentos/AUH_en_ Argentina.pdf. Acessado em 11 de junho de 2011.

Andrenacci, L.; F. Repetto. (2006) "Universalismo, ciudadanía y Estado en la política social latino-americana”. Disponível em http://www.rau.edu.uy/fcs/dts/Politicassociales/Andrenacci_Repetto.pdf.

ARGENTINA. DECRETO LEI 1602/09 (2009) Disponível em http://www.argentina.ar/advf/ documentos/4ae9de593aafd.pdf. Acessado em 30/junho/ 2011.

ARGENTINA. LEY 26.425. Disponível em http://www.planetaius.com.ar/foroderecho/ley-26-425-sistema-integrado-previsional-argentino-sipa-3925. Acesso em 29 de outubro de 2011.

BANCO MUNDIAL (2000) World Development Report 2000/2001: attacking poverty. Washington, D. C, Oxford University Press.

BOYADJIAN, Ana Carolina Paes de Barros (2009) Os programas de transferência de renda em países específicos da América Latina e no Brasil. São Paulo: PUCRS, 2009. Dissertação (Mestrado). Programa de Pós-Graduação em Economia Política, Pontifícia Universidade Católica de São Paulo.

BRASIL (2004) Lei n. 10.836/2004. Disponível:http://www.planalto.gov.br/ccivil_03/_ato20042006/2004/lei/110.836.htm. Acessado em 08 de julho de 2011.

CAIXA ECONÔMICA FEDERAL. Disponível em https://www.beneficiossociais.caixa.gov.br/consulta/ beneficio/04.01.00-00_00.asp. Acesso em 15 de julho de 2011.

COMISSÃO ECONÔMICA PARA A AMÉRICA LATINA E O CARIBE - CEPAL (2000), Panorama social da América Latina - 1999-2000. Santiago do Chile.

COMISSÃO ECONÔMICA PARA A AMÉRICA LATINA E O CARIBE - CEPAL (2009) Panorama social da América Latina - 2009. Santiago do Chile.

COMISSÃO ECONÔMICA PARA A AMÉRICA LATINA E O CARIBE- CEPAL (2011) Planificar, presupuestar y evaluar en América Latina y el Caribe, Disponível em www.cepal.org/ilpes/noticias/ paginas/1/33541/megaobjetivo.ppt. Acesso em 15 de julho de 2011.

D’ELIA, Vanessa; CALABRIA, Alejandro; CALERO, Analia; Gaiada, Julio e Rottenschweiler, Sergio (s.d.) "Asignación Universal por Hijo para Protección Social: Una política de inclusión para los 
más vulnerables”. Cidade do México, Revista Seguridad Social, nº 260, s. d. Disponível em http:// www.ciss.org.mx/index_es.php?mod=revista Acesso em 09 de abril de 2012.

DUARTE, Gisléia Benini; Sampaio, Breno e Sampaio, Yony (2009) "Programa Bolsa Família: impacto das transferências sobre os gastos com alimentos em famílias rurais". Revista de Economia e Sociologia Rural, vol 47, $\mathrm{n}^{\circ}$ 4. Disponível em http://www.scielo.br/scielo.php?pid=S0103-20032009000400005\&script=sci_arttext. Acesso em 15 de julho de 2011.;

FLEURY, Sônia (1998) "Política social, exclusión y equidad en América Latina en los 90". Nueva Sociedad, $\mathrm{n}^{\circ}$ 156. Disponível em http://www.nuso.org/upload/articulos/2698_1.pdf. Acesso em 15 de julho de 2011.

GOLBERT, Laura Susana (2010) "De la Sociedad de Beneficiencia a los derechos sociales". Buenos Aires, Ministerio de Trabajo, Empleo y Seguridad Social. Disponível em http://www.trabajo.gov.ar/left/ estadisticas/descargas/bess/LIBRO_De-la-Sociedad-de-la-Beneficencia2.pdf. Acesso em 7 de setembro de 2011.

INSTITUTO BRASILEIRO DE GEOGRAFIA E ESTATÍ́STICA. Pesquisa Mensal de Emprego. Banco Sidra. Disponível em http://www.ibge.gov.br/home/estatistica/indicadores/trabalhoerendimento/ pme_nova/default.shtm. Acesso em 14 de julho de 2011.

Instituto de Pesquisas Aplicadas. Objetivos de Desenvolvimento do Milênio - Relatório Nacional de Acompanhamento. Brasília, IPEA, março, 2010. Disponível: http://agencia.ipea.gov.br/images/stories/PDFs/100408_relatorioodm.pdf. Acessado em 08 de julho de 2011.

LANDIM Junior, Paulo Henrique (2009) "Os efeitos do Programa Bolsa Família sobre a economia dos municipios brasileiros”, Instituto de Ensino e Pesquisa, São Paulo. Disponível em www.ipc-undp. org/publications/mds/33P.pdf.

MARQUES, Rosa Maria. (2005) “A importância do Bolsa Família nos municípios brasileiros”, Cadernos de Estudos Desenvolvimento Social em Debate, n.1, Brasília: Ministério do Desenvolvimento Social e Combate à Fome, Secretaria de Avaliação e Gestão da Informação.

MARQUES, Rosa Maria; Leite, Marcel Guedes; Mendes, Áquilas; e Ferreira, Mariana Ribeiro Jansen (2009) "Discutindo o papel do Programa Bolsa Família na decisão das eleições presidenciais brasileiras de 2008", Revista de Economia Política, vol. 29, nº 1 (113).

MARX, Karl (1982) O Capital. São Paulo, Difel.

Organización Internacional del Trabajo (OIT). Panorama Laboral 2010. Lima: OIT / Oficina Regional para América Latina y el Caribe, 2010.

ROCA, Emilia. “Asignación Universal por Hijo (AUH): extensión de las asignaciones familiares”. Buenos Aires, Revista de Debate Público - Reflexión de Trabajo Social. Disponível em http://www. trabajosocial.fsoc.uba.ar/web_revista/PDF/6_roca.pdf. Acesso em 09 de abril de 2012.

SAWYER, Diana Oya (2007) Avaliação do impacto do Programa Bolsa Família. Brasília, MDS.

SILVEIRA NETO, Raul da Mota (2010) "Impacto do Programa Bolsa Família sobre a frequência à escola: estimativa a partir de informações da Pesquisa Nacional por amostra de domicílio (PNAD)". In: IPEA. Bolsa Família 2003 - 2010: avanços e desafios. Brasília: IPEA, volume 2.

SINGER, André (2009) "Raízes sociais e ideológicas do lulismo". São Paulo, Novos Estudos Cebrap, n ${ }^{\circ}$ 85: $83-99$.

SOARES, Sergei; De Souza, Pedro Herculano G. Ferreira; OSÓRIO, Rafael Guerreiro E Silveira, Fernando Gaiger (2010). "Os impactos do benefício do Programa Bolsa Família sobre a desigualdade e a pobreza”. In: IPEA. Bolsa Família 2003 - 2010: avanços e desafios. Brasília: IPEA, volume 2,.

SOARES, Segei; Leichsenring, Alexandre R. "Precariedade, laboral, volatilidade de renda e a cobertura do Programa Bolsa Família”. In: IPEA. Bolsa Família 2003 - 2010: avanços e desafios. Brasília: IPEA, volume 1, 2010.

SOLANO, Carlos Barba (coordenador). Proyecto: La reforma social en América Latina en la encrucijada. Transferencias condicionadas de ingresos o universalización de la proteción social. Fundación Carolina "Grupo de Trabajo Pobreza y Políticas Sociales. CLACSO, dezembro de 2009. Acessível em http://pt.scribd.com/doc/56286801/Comparacion-Programa-Jefes-y-Jefas-de-Hogar-Desocupados-Plan-Familia-por-la-Inclusion-Social-y-Asignacion-Universal-por-Hijo-Argentina-Salta-Alva.

TIRENNI, Jorge. La asignación universal por hijo. Sem data. Disponível: http://www.flacso.org.ar/politicaspublicas/publicaciones/ppe.

UGINO, Camila Kimie e MARQUES, Rosa Maria (2011) “As reformas previdenciárias brasileiras: o cerco à proteção social”, In Anais do XVI Encontro Nacional de Economia Política. Uberlândia, 2011. 